\title{
Histopathological Patterns and Characteristics of Abnormal Cervical Smear in Madinah Region of Saudi Arabia
}

\author{
Hala Mohammed Yousif ${ }^{1}$, Abdulkader Mohammed Albasri ${ }^{1 *}$, Mariam \\ Mohammed Alshanqite ${ }^{2}$, Hashim Mohamed Missawi ${ }^{3}$
}

\begin{abstract}
Cervical cancer is a major public health problem that continues to be one of the leading female genital cancers worldwide. In the kingdom of Saudi Arabia (KSA), cervical cancer ranks the fifteenth most frequent cancer among females. This study is the first published research study addressing the screening of cervical cancer in Madinah region of KSA. Aim: To evaluate the abnormal cytological entities detected by cervical Pap smear in Madinah region of KSA and to compare the results with other national and international studies. Methods: This retrospective case-control study was conducted in the Departments of Obstetrics and Gynecology, and Histopathology at the Maternity and Children Hospital (MCH), Madinah, KSA from January 2013 to December 2015. Results: Of the 1594 cases reviewed, only 38 cases $(2.4 \%)$ had epithelial cell abnormalities. High grade squamous intraepithelial lesions (HSIL) and low grade squamous intraepithelial lesions (LSIL) were the most common diagnosis categories, and cervical cancer accounted for $36.8 \%$ of the total cases for each, followed by atypical squamous cells of uncertain significance (ASCUS) found in $(15.9 \%)$. Squamous cell carcinoma (SCC ) was found in $(5.3 \%)$ of the cases. Patients with abnormal epithelial changes had higher parity $(\mathrm{P}=0.021)$ and presented more with a complaint of postcoital bleeding $(\mathrm{P}<0.0001)$, tend to have abnormal cervical appearance $(\mathrm{P}=0.004)$, more likely bleeding on touch $(\mathrm{P}=0.001)$ and associated with cervical erosion $(\mathrm{P}=0.014)$. Conclusion: The study showed a relatively low prevalence of epithelial cell lesions. These lesions were mainly squamous cell lesions harbored by females who have an abnormal cervical appearance, and those with high parity who were lacking cervical screening program.
\end{abstract}

Keywords: Cervical cancer- Pap smear- Madinah- Saudi Arabia

Asian Pac J Cancer Prev, 20 (5), 1303-1307

\section{Introduction}

Cervical cancer is the fourth most common cancer among females worldwide with an estimated 570,000 new cases in 2018 representing $6.6 \%$ of all female cancers (GLOBOCAN, 2018), with the vast majority occurring in developing countries (Abudukadeer et al., 2015). In the Kingdom of Saudi Arabia (KSA), the most recent Saudi Cancer Registry (SCR) report showed there were 117 new cases of cervical cancer diagnosed in 2014, accounting for $1.8 \%$ of diagnosed cancer cases in females and making it the 15th most frequent cancer in the female Saudi population (Annual Cancer Incidence Report for Saudi Cancer Registry, 2017).

Although the incidence of cervical cancer in KSA is very low, the involvement of human papilloma virus (HPV) infection in this malignancy is comparable to the rest of the world with HPV-16 and HPV-18. Cervical cancer vaccination is expected to protect against more than two-thirds of cervical cancer in KSA (Alsbeih, 2014).
National Health Services (NHS) in the United Kingdom (UK) concluded that, in any case of cancer cervix developed at the average age of 46-50, this may entail that carcinogenesis had started 20 years prior, so cervical screening now starts at 25 years of age (Sasieni et al., 2009; Cervical screening, 2015). Cervical screening in females aged 20-24 has little or no impact on rates of invasive cervical cancer up to age 30 , while screening older females leads to a substantial reduction in incidence and mortality from cervical cancer (Sasieni et al., 2009). Although a localized Saudi cervical screening program was established in 2009 to promote routine screening for cervical cancer with HPV testing for all females above the age of 30 who have been married for at least three years, Pap smear screening is still performed on an opportunistic basis in Saudi Arabia (Al-Kadri et al., 2015).

The United Kingdom's cervical screening program changed its screening method from the conventional Pap method to liquid-based cytology (LBC) in 2008 (Liptak and Barnetson, 2012). Liquid cytology produced

${ }^{1}$ Department of Pathology, ${ }^{2}$ Faculty of Medicine, Taibah University, Universities Road, ${ }^{3}$ Department of Pathology, Maternity and Children Hospital, Alhezam Road, Al-Madinah Al-Munawwarah, Kingdom of Saudi Arabia. *For Correspondence: abdbasri@hotmail.com 
a significantly higher yield of histologic high-grade lesions compared with conventional Pap smears (Strander et al., 2007). While other studies showed significant improvements in achieving the target diagnosis over time for squamous dysplasia using both modalities (Marquart et al., 2015), both types of cytological screening are considered acceptable methods of cervical cancer screening by the American College of Obstetricians and Gynecologists (ACOG Committee on Practice Bulletins-Gynecology, 2009). To unify systems of reporting cervical/vaginal cytological diagnosis, the National Cancer Institute Workshop proposed the Bethesda System of nomenclature in 1988 (Al-Kadri et al., 2015).

No similar recent study has been performed in the Madinah region of KSA that allows a clear view of the prevalence of cervical cancer and its characteristics. Therefore, this study aimed to explore the cytopathological pattern of cervical Pap smears in the Madinah region of KSA and to assess the clinical and personal characteristics of patients who were diagnosed with abnormal Pap smears.

\section{Materials and Methods}

This retrospective case-control study was conducted in the Departments of Obstetrics and Gynecology, and Histopathology at the Maternity and Children Hospital (MCH), Madinah, KSA from January 2013 to December 2016. Gynecologists collected the smear utilizing a cytobrush from the uterine cervix transformation zone. The cytobrush was then placed in a liquid-based cytology transport preservative, SurePath. Smears were collected from patients who attended gynecology clinics complaining about different symptoms. Few patients came intentionally without symptoms for screening purposes. Smears were evaluated by histopathologists and were diagnosed and reported according to the Bethesda System III for Reporting Cervical Cytology 2001.

All females of all ages and nationalities who had their Pap smears performed between January 2013 and December 2015 were included in the study, and all reports gave the complete diagnosis despite non-uniformities in the pattern; unsatisfactory Pap smears and repeated smears after short intervals with the same diagnosis were excluded.

A total of 1,594 cases were reviewed for the study with 38 cases yielding abnormal epithelial lesions, which were considered study cases (group I or case); 77 normal pap smears were considered the control group (group II or control) and were selected randomly from the normal smears throughout the whole three years of the study. In addition, 25, 25, and 27 normal smears were selected from the years 2013, 2014, and 2015, respectively, based on patients' laboratory numbers. Paper and electronic medical records of all patients in both groups were reviewed, and Pap smear results, history, clinical data, and demographic data were collected. Three main categories of smear cytology were identified: normal, abnormal, and unsatisfactory. The abnormal category included epithelial cell lesions (ECL) and no intraepithelial lesion or malignancy (NILM). ECL included high-grade squamous intraepithelial lesion (HSIL), low-grade squamous intraepithelial lesion (LSIL), atypical squamous cells of unknown significance(ASCUS), squamous cell carcinoma (SCC), atypical glandular (AGC), and endocervical adenocarcinoma (ECA). No intraepithelial lesion or malignancy included benign categories: inflammation, repair, atrophic, and hormonal changes. Smears obscured by blood and inflammation, smears that were acellular, and those just showing endocervical cells were all allocated within the unsatisfactory category. All the statistical analysis was done using the Statistical Package for the Social Sciences (SPSS) version 20 (SPSS Inc., Chicago, USA).

Ethical approval for the study was obtained from the Committee of Scientific Research Ethics at MCH. Patients' demographic and clinical data were secured and were accessible only to researchers.

\section{Results}

Between January 2013 and December 2015, 1594 Pap smears were evaluated. Only 38 cases $(2.4 \%)$ had epithelial cell abnormalities. Table 1 shows the distribution of evaluated smears and epithelial cell lesions positive smears according to year. More than half (55\%) of ECL cases were diagnosed in 2015.

Table 2 presents the clinical characteristics of female patients included in the study. The mean ages were similar in both study groups: $46.7 \pm 11.0$ years for the case group and $46.9 \pm 10.7$ years for the control group. While patients in the case group had higher parity compared to patients in the control group $(\mathrm{P}=0.021)$, both groups gave a similar percentage of using an intrauterine contraceptive device (IUCD) and hormones $(\mathrm{P}=0.85)$.

Females who attended the clinics complained of different symptoms. Postmenopausal bleeding was the most common cause leading to clinic attendance at 31 patients $(27 \%)$, while only $15(15.7 \%)$ came intentionally for screening. Previous abnormal smears had a significant relation with ECL cases $(\mathrm{P}=0.020)$. Case group patients were more likely to present complaints from postcoital bleeding $(\mathrm{P}<0.000)$, and they were more likely to have an abnormal-looking cervix $(\mathrm{P}=0.004)$; their services bled easily on touch $(\mathrm{P}=0.001)$ and tended to be more eroded $(\mathrm{P}=0.014)$.

A total of 23 Pap smears $(1.5 \%)$ were considered unsatisfactory or inadequate for evaluation. Pathological findings were detected in 1039 smears (65\%). Epithelial

Table 1. The Distribution of Evaluated Smears and Epithelial Cell Lesions Positive Smears According to Year

\begin{tabular}{lcc}
\hline Year & $\begin{array}{c}\text { Number of evaluated } \\
\text { smears (\%) }\end{array}$ & $\begin{array}{c}\text { Number of ECL } \\
\text { smears (\%) }\end{array}$ \\
\hline 2013 & $490(30.7 \%)$ & $9(24.3 \%)$ \\
2014 & $490(30.7 \%)$ & $8(21.6 \%)$ \\
2015 & $614(38.5 \%)$ & $21(55 \%)$ \\
Total & 1594 & 38 \\
\hline
\end{tabular}

ECL, Epithelial cell lesion 
Table 2. Clinical Characteristics of Patients with Normal Versus Patients with Abnormal Smears

\begin{tabular}{|c|c|c|c|c|}
\hline Patient characteristics & Case $(n=38)$ & Control $(n=77)$ & OR $(95 \% \mathrm{CI})$ & P-value \\
\hline Age, mean \pm SD & $46.7 \pm 11.0$ & $46.9 \pm 10.7$ & $0.98(0.39-2.41)$ & 0.921 \\
\hline Parity, mean \pm SD & $4.5 \pm 2.8$ & $3.5 \pm 2.3$ & $0.56(1.14-5.75)$ & 0.021 \\
\hline IUCD use & 8 & 15 & $0.91(0.35-2.36)$ & 0.845 \\
\hline Hormones use & 12 & 23 & $0.92(0.39-2.13)$ & 0.851 \\
\hline \multicolumn{5}{|l|}{ Patients symptoms } \\
\hline Postcoital bleeding & 11 & 2 & $15.28(3.18-73.40)$ & 0 \\
\hline Postmenopausal bleeding & 10 & 21 & $0.952(0.39-2.29)$ & 0.913 \\
\hline Screen purposes & 0 & 15 & $0.33(0.09-1.20)$ & 0.002 \\
\hline Irregular bleeding & 5 & 8 & $1.31(0.39-4.30)$ & 0.659 \\
\hline Dyspareunia & 4 & 8 & $1.02(0.29-3.61)$ & 0.982 \\
\hline Vaginal discharge & 0 & 11 & $0.33(0.07-1.59)$ & 0.151 \\
\hline Previous abnormal smear & 8 & 5 & $3.84(1.16-12.69)$ & 0.02 \\
\hline Premenopausal & 0 & 7 & $0.65(0.56-0.75)$ & 0.056 \\
\hline \multicolumn{5}{|l|}{ Cervical clinical findings } \\
\hline Abnormal appearance & 23 & 25 & $3.19(1.42-7.15)$ & 0.004 \\
\hline Bleeding on touch & 5 & 0 & $0.30(0.23-0.39)$ & 0.001 \\
\hline Erosion & 10 & 7 & $3.57(1.24-10.32)$ & 0.014 \\
\hline Polyp & 2 & 3 & $1.37(0.22-8.57)$ & 0.735 \\
\hline Cervicitis & 6 & 13 & $0.92(0.32-2.66)$ & 0.882 \\
\hline
\end{tabular}

IUCD; Intrauterine device

cell lesions were seen in 38 smears (2.4\%). Details of pathological findings are shown in Table 3.

Table 3. Number and Percentage of the Specific Findings of All the Pap Smears Based on the Bethesda System 2001 with Respect to Mean Age

\begin{tabular}{|c|c|c|}
\hline Smear result & $\begin{array}{c}\text { Mean age } \\
\quad \pm \mathrm{SD}\end{array}$ & $\begin{array}{c}\text { Number } \\
\text { (\% of abnormal) }\end{array}$ \\
\hline Unsatisfactory & & $23(1.5 \%)$ \\
\hline Normal & $41.9 \pm 9.09$ & $523(33 \%)$ \\
\hline ECL & $46.68 \pm 11.08$ & $38(2.4 \%)$ \\
\hline HSIL & $45.5 \pm 10.92$ & $14(36.8 \%)$ \\
\hline LSIL & $43.2 \pm 10.22$ & $14(36.8 \%)$ \\
\hline ASCUS & $47.7 \pm 12.01$ & $6(15.9 \%)$ \\
\hline Squamous cell carcinoma & $50 \pm 13.90$ & $2(5.3 \%)$ \\
\hline EAC & $80 \pm 19.78$ & $1(2.6 \%)$ \\
\hline $\mathrm{AGC}$ & $69 \pm 15.33$ & $1(2.6 \%)$ \\
\hline NILM & $41.26 \pm 9.01$ & $1010(63.4 \%)$ \\
\hline Inflammatory & $40.27 \pm 8.99$ & $866(86.5 \%)$ \\
\hline Reactive & $46.10 \pm 11.01$ & $20(1.99 \%)$ \\
\hline Non specific findings & $41.25 \pm 9.02$ & $32(3.19 \%)$ \\
\hline Atrophy & $54.40 \pm 14.32$ & $25(2.49 \%)$ \\
\hline Estrogenic influence & $39.88 \pm 7.55$ & $27(2.69 \%)$ \\
\hline Progesterone influence & $33.55 \pm 8.35$ & $30(2.99 \%)$ \\
\hline Cervical ectopy & $60.00 \pm 20.01$ & $1(0.09 \%)$ \\
\hline Total & & 1,594 \\
\hline
\end{tabular}

\section{Discussion}

The prevalence of ECL in the present study was $2.4 \%$, which is one of the lowest rates of prevalence in KSA, Gulf Cooperation Council (GCC) countries, and other countries. Previous studies from different areas in KSA showed ECL prevalence rates ranging from 1.7\% to $17.2 \%$ (Al-Kadri et al., 2015; Jamal and Al-Maghrabi, 2003; Al-Jaroudi and Hussain, 2010 and Altaf and Mufti, 2012). Regarding GCC countries, the largest study was carried in Kuwait with an evaluation of 140,404 smears throughout 21 years in which the reported prevalence rate of ECL was 4.3\% (Table 4) (Kapila et al., 2015).

In our study, ASCUS was seen in only 6 smears (16.2\%) of the epithelial lesions, while LSIL and HSIL were the most frequent lesions, accounting for $36.8 \%$ of the total cases for each. In most Saudi studies, ASCUS represented the most common finding (Al-Kadri et al., 2015 and Altaf and Mufti, 2012). Similar studies from United Arab Emirates (UAE) and Turkey reported that ASCUS was the most common category (Alzaabi and Al Muqbali, 2015; Korkmaz and Gencer, 2014).

The mean age of the whole studied population was 41.26 years, and the mean age of the ECL smears was 46.68 years, while the means of age in different diagnostic categories of ECL (ASCUS, LSIL, and HSIL) were close but showed a slight increase in patients with cervical cancer. These figures are close to the figures reported in studies from KSA (Al-Kadri et al., 2015 and Altaf and Mufti, 2012) but higher than the figures reported in studies outside KSA (Alzaabi and Al Muqbali, 2015).

The lack of the cervical screening programs in this region is most likely to cause a delay in diagnosis of ECL. This may explain the higher age of patients in this 
Table 4. Prevalence of the Abnormal Cytological Entities Detected by Cervical Pap Smear in Different Studies

\begin{tabular}{|c|c|c|c|c|c|c|c|c|c|}
\hline $\begin{array}{l}\text { Study's } \\
\text { author }\end{array}$ & Year & Total number & $\begin{array}{l}\text { ECL } \\
\text { (n) } \%\end{array}$ & $\begin{array}{l}\text { ASCUS } \\
\text { (n) } \%\end{array}$ & $\begin{array}{l}\text { HSIL } \\
\text { (n) } \%\end{array}$ & $\begin{array}{l}\text { LSIL } \\
\text { (n) } \%\end{array}$ & $\begin{array}{l}\text { SSC } \\
\text { (n) } \%\end{array}$ & $\begin{array}{l}\text { ECA } \\
\text { (n) } \%\end{array}$ & $\begin{array}{l}\text { AGUS } \\
\text { (n) } \%)\end{array}$ \\
\hline Al-Kadri H & 2015 & 19,650 & $\begin{array}{c}841 \\
(4.30 \%)\end{array}$ & $497(59 \%))$ & $\begin{array}{c}43 \\
(5.10 \%)\end{array}$ & $\begin{array}{c}170 \\
(20.20 \%)\end{array}$ & $\begin{array}{c}8 \\
(1 \%)\end{array}$ & $\begin{array}{c}21 \\
(2.50 \%)\end{array}$ & $\begin{array}{c}53 \\
(6.30 \%)\end{array}$ \\
\hline $\begin{array}{l}\text { Al-Jaroudi } \\
\text { D }\end{array}$ & 2010 & 241 & $\begin{array}{c}7 \\
(2.90 \%)\end{array}$ & $\begin{array}{c}3 \\
(42.90 \%)\end{array}$ & $\begin{array}{c}1 \\
(14.30 \%)\end{array}$ & $\begin{array}{c}2 \\
(28.60 \%)\end{array}$ & - & - & $\begin{array}{c}1 \\
(14.30 \%)\end{array}$ \\
\hline Altaf F & 2012 & 7,297 & $\begin{array}{c}1254 \\
(17.20 \%)\end{array}$ & $\begin{array}{c}674 \\
(53.70 \%)\end{array}$ & $\begin{array}{c}63 \\
(5 \%)\end{array}$ & $\begin{array}{c}198 \\
(15.80 \%)\end{array}$ & $\begin{array}{c}4 \\
(0.30 \%)\end{array}$ & - & - \\
\hline Kapila K & 2015 & 140,404 & $\begin{array}{c}6013 \\
(4.30 \%)\end{array}$ & $\begin{array}{c}3212 \\
(53.40 \%)\end{array}$ & $\begin{array}{c}294 \\
(4.90 \%)\end{array}$ & $\begin{array}{c}1,279 \\
(21.30 \%)\end{array}$ & $\begin{array}{c}118 \\
(2 \%)\end{array}$ & - & $\begin{array}{c}1092 \\
(18.20 \%)\end{array}$ \\
\hline Alzaabi M & 2015 & 4,593 & $\begin{array}{c}225 \\
(4.90 \%)\end{array}$ & $\begin{array}{c}114 \\
(64 \%)\end{array}$ & $\begin{array}{c}27 \\
(12 \%)\end{array}$ & $\begin{array}{c}72 \\
(32 \%)\end{array}$ & $\begin{array}{c}2 \\
(0.90 \%)\end{array}$ & - & $\begin{array}{c}5 \\
(2.20 \%)\end{array}$ \\
\hline Korkmaz F & 2014 & 3,813 & $\begin{array}{c}73 \\
(1.90 \%)\end{array}$ & $\begin{array}{c}37 \\
(50.70 \%)\end{array}$ & $\begin{array}{c}4 \\
(5.50 \%)\end{array}$ & $\begin{array}{c}19 \\
(26 \%)\end{array}$ & $\begin{array}{c}2 \\
(2.70 \%)\end{array}$ & $\begin{array}{c}2 \\
(2.70 \%)\end{array}$ & $\begin{array}{c}3 \\
(4.10 \%)\end{array}$ \\
\hline $\mathrm{CS}$ & 2015 & 1,594 & $\begin{array}{c}38 \\
(2.40 \%)\end{array}$ & $\begin{array}{c}6 \\
(15.90 \%)\end{array}$ & $\begin{array}{c}14 \\
(36.80 \%)\end{array}$ & $\begin{array}{c}14 \\
(36.80 \%)\end{array}$ & $\begin{array}{c}2 \\
(5.30 \%)\end{array}$ & $\begin{array}{c}1 \\
(2.60 \%)\end{array}$ & $\begin{array}{c}1 \\
(2.60 \%)\end{array}$ \\
\hline
\end{tabular}

ECL, Epithelial cell lesion; ASCUS, Atypical squamous cells of undetermined significance; HSIL, High squamous intraepithelial lesion; LSIL, Low squamous intraepithelial lesion; SCC, Squamous cells carcinoma; EAC, Endocervical adenocarcinoma; AGUS, Atypical glandular cells of undetermined significant; CS, Current study

study. Table 4 lists some studies and their results. Many social themes influence females' perceptions of cervical cancer in KSA. The disease is thought socially to carry the indication of the presence of extramarital sexual relations, which is a social disgrace. This belief has a significant negative impact on the acceptance of females coming for cervical screening (Khan, 2015). The health sector in KSA has made an effort in screening for cervical cancer through some screening programs. The local cervical screening program in Jeddah is one of them (Al-Kadri et al., 2015). The National Cervical screening program has not been implemented yet, and Pap smear screening is still performed on an opportunistic basis during females' visits to health facilities (Al-Kadri et al., 2015).

Using IUCDs was not associated with ECL in our study compared to some studies which linked the use of IUCDs to a higher risk of developing abnormal smears (Yasmin and Mukherjee, 2012) and other studies which showed an inverse relationship of using IUCDs and ECL (Castellsague et al., 2011). Contradicting studies linking the use of hormones with a higher tendency to develop epithelial lesions (Gavric and Takac, 2010), our study revealed an insignificant difference between case and control groups in using the hormone.

Limitation of this study could include the number of evaluated patients and ECL cases, which were considered too low to determine the disease category characteristics. Many studies from KSA had a larger studied population from larger specialized centers, and some of these centers had a local screening program. More patients from previous and coming years should be included to lessen this limitation and determine what was its true prevalence or whether it resulted from a low number of evaluated patients in this region.

This study concluded that the prevalence of cervical epithelial lesions is low if compared to other areas in KSA and other countries. The study highlights that females aged 46.6 years or above harbor the bulk of premalignant and malignant lesions in cervical smears; these females tend to have higher parity and more frequent postcoital bleeding and have an abnormal inspection of cervix uteri. This signifies that these females are among the under-users of cytological screening. Hence, an efficient cervical cancer screening program is needed. More extended studies including assessment of HPV prevalence will be valuable for further exploration of the magnitude of this health problem.

\section{Acknowledgements}

We extend our sincere thanks to The Deanship of Scientific Research, Taibah University, Madinah, Saudi Arabia, for their constant encouragement and support. We would also like to thank " Scribendi, the Editing and Proofreading Services for English Documents (https:// www.scribendi.com/) "for the English Language editing of the Manuscript.

\section{References}

Abudukadeer A, Azam S, Mutailipu AZ, et al (2015). Knowledge and attitude of Uyghur women in Xinjiang province of China related to the prevention and early detection of cervical cancer. World J Surg Oncol, 13, 110.

ACOG Committee on Practice Bulletins-Gynecology (2009). ACOG Practice Bulletin no. 109: Cervical cytology screening. Obstet Gynecol, 114, 1409-20.

Al-Jaroudi D, Hussain TZ (2010). Prevalence of abnormal cervical cytology among Subfertile Saudi women. Ann Saudi Med, 30, 397-400.

Al-Kadri H, Kamal M, Bamuhair S, Omair A, Bamefleh H (2015). Prevalence and characteristics of abnormal Papanicolaou smear in Central Saudi Arabia. Saudi Med $J$, 36, 117-22

Alsbeih G (2014). HPV infection in cervical and other cancers in Saudi Arabia: implication for prevention and vaccination. Front Oncol, 4, 65.

Altaf F, Mufti S (2012). Pattern of cervical smear abnormalities using the revised Bethesda system in a tertiary care hospital in Western Saudi Arabia. SMJ, 33, 634-39. 
Alzaabi M, Al Muqbali S (2015). Age specific cytological abnormalities in women screened for cervical cancer in the Emirate of Abu Dhabi. Asian Pac J Cancer Prev, 16, 6375-79.

Annual Cancer Incidence Report for Saudi Cancer Registry (SCR) (2014) [Internet]. Available from https://nhic.gov.sa/ eServices/Documents/2014.pdf. [Accessed on 22-10-2018].

Castellsague X, Diaz M, Vaccarella S, et al (2011). Intrauterine device use, cervical infection with human papillomavirus, and risk of cervical cancer: a pooled analysis of 26 epidemiological studies. Lancet Oncol, 12, 1023-31.

Gavric V, Takac I (2010). Use of various contraceptives and human papillomavirus 16 and 18 infections in women with cervical intraepithelial neoplasia. Int J STD AIDS, 21, 424-7.

GLOBOCAN (2018). Estimated cancer incidence, mortality and prevalence worldwide in 2018. 2018.http://gco.iarc.fr/ today/data/factsheets/cancers/23-Cervix-uteri-fact-sheet.pdf

Jamal A, Al-Maghrabi JA (2003). Profile of PAP smear cytology in the Western region of Saudi Arabia. Saudi Med J, 24, 1225-9.

Kapila K, Sharma PN, George SS, et al (2015). Trends in epithelial cell abnormalities observed on cervical smears over a 21-year period in a tertiary care hospital in Kuwait. SQUMJ, 15, 112-5.

Khan S (2015). Perspectives on cervical cancer screening among educated Muslim women in Dubai (the UAE): a qualitative study. BMC Women Health, 15, 90.

Korkmaz F, Gencer M (2014). Outpatient screening results of Pap Smears. AJCI, 8, 17-20.

Liptak P, Barnetson RJ (2012). Liquid-based cervical cytology in the United Kingdom and South Africa. J Eur CME, 30, 45-8.

Marquart L, Pelecanos AM, Perkins G, et al (2015). Which are more correctly diagnosed: conventional Papanicolaou smears or Thinprep samples? A comparative study of 9 years of external quality-assurance testing. Cancer Cytopathol, 123, 108-16.

Sasieni P, Castanon A, Cuzick J (2009). Effectiveness of cervical screening with age: population based case-control study of prospectively recorded data. $B M J, 339, \mathrm{~b} 2968$.

Strander B, Andersson-Ellström A, Milsom I, Rådberg T, Ryd W (2007). Liquid-based cytology versus conventional Papanicolaou smear in an organized screening program: a prospective randomized study. Cancer, 111, 285-91.

Yasmin S, Mukherjee A (2012). A cyto-epidemiological study on married women in reproductive age group (15-49 years) regarding reproductive tract infection in a rural community of West Bengal. Indian J Public Health, 56, 204-9.

\section{c) (i) (8)}

This work is licensed under a Creative Commons AttributionNon Commercial 4.0 International License. 